\title{
Residências terapêuticas e reforma psiquiátrica em produções discursivas da população
}

\author{
Thelma Maria Grisi Velôso \\ Pedro de Oliveira Filho \\ Élida Dantas do Nascimento \\ Pauleska Asevedo Nóbrega \\ Roseane Barros Pinto
}

\section{SciELO Books / SciELO Livros / SciELO Libros}

SILVEIRA, MFA., and SANTOS JUNIOR, HPOS., orgs. Residências terapêuticas: pesquisa e prática nos processos de desinstitucionalização [online]. Campina Grande: EDUEPB, 2011. 320 p. ISBN $978-$ 85-7879-063-9. Available from SciELO Books $<\underline{\text { http://books.scielo.org }>\text {. }}$

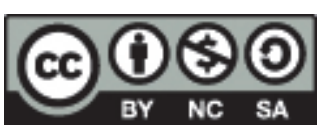

All the contents of this work, except where otherwise noted, is licensed under a Creative Commons Attribution-Non Commercial-ShareAlike 3.0 Unported.

Todo o conteúdo deste trabalho, exceto quando houver ressalva, é publicado sob a licença Creative Commons Atribuição Uso Não Comercial - Partilha nos Mesmos Termos 3.0 Não adaptada.

Todo el contenido de esta obra, excepto donde se indique lo contrario, está bajo licencia de la licencia Creative Commons Reconocimento-NoComercial-CompartirIgual 3.0 Unported. 


\title{
Residências Terapêuticas e Reforma Psiquiátrica em produções discursivas da população
}

\author{
Thelma Maria Grisi Velôso \\ Pedro de Oliveira Filho \\ Élida Dantas do Nascimento \\ Pauleska Asevedo Nóbrega \\ Roseane Barros Pinto
}

\section{Introdução}

As propostas de saúde pública que surgiram no bojo das discussões promovidas, nos anos 70, pelo movimento de transformação da saúde pública nacional, a chamada Reforma Sanitária, convidam à reflexão e à investigação científica. Com esse propósito, pretende-se, neste texto, ampliar a discussão sobre a proposta de Reforma Psiquiátrica no Brasil.

As críticas feitas à Psiquiatria Asilar desembocaram no desmantelamento de uma estrutura que oprimia, controlava, punia, vigiava e segregava os chamados loucos no interior das organizações manicomiais. Nesse sentido, a "desinstitucionalização não se restringe à reestruturação técnica, de serviços, de novas e modernas terapias: torna-se um processo complexo de recolocar o problema, 
de reconstruir saberes e práticas, de estabelecer novas relações" (AMARANTE, 2007).

No Brasil, o movimento de combate à psiquiatria asilar se materializou através da Lei de Reforma Psiquiátrica (Lei 10.216/2001), cujo objetivo fundamental é o resgate da liberdade e do direito à cidadania das pessoas classificadas como loucas. Por essa razão, seguindo, sobretudo, a proposta da Psiquiatria Democrática Italiana, manicômios foram fechados, e novos espaços foram criados - o chamado modelo substitutivo, baseado na criação de centros de saúde mental, serviços abertos e extra-hospitalares na comunidade, e que servem como referenciais nos momentos de crise. Criaram-se também as residências terapêuticas, uma alternativa para aqueles que, com o fechamento dos manicômios, perdem os vínculos com a família e necessitam de condições para reconstruir os laços sociais. Essas residências se localizam no espaço urbano e são habitadas por, no máximo, oito moradores, objetivando promover sua reabilitação psicossocial e inseri-los na comunidade (BRASIL, 2004).

A inserção dos denominados loucos na comunidade é, como vimos, um dos objetivos explícitos das residências terapêuticas. Não é uma tarefa simples, pois se sabe que um dos maiores obstáculos para a plena cidadania dos denominados loucos, no mundo ocidental, são os discursos sobre a loucura, que se reproduzem, há séculos, no cotidiano das sociedades ocidentais. Por essa razão, é extremamente relevante saber se e como esses discursos estão sendo mobilizados na sociedade brasileira, quando as residências terapêuticas começam a fazer parte da nossa paisagem urbana.

Este trabalho procura dar uma pequena, mas significativa contribuição a respeito desse aspecto. Para isso, tenta responder à seguinte questão: Quais os sentidos produzidos pelas pessoas que moram nas proximidades das residências terapêuticas, em Campina Grande-PB, sobre essas residências e as pessoas que nelas habitam? 
Propusemo-nos a estudar a produção de sentidos com base em uma ampla perspectiva teórica da psicologia social, que vem destacando o papel da linguagem na produção da vida social (SPINK; FREZZA, 1999; POTTER, 1998; WETHERELL; POTTER, 1992; POTTER; WETHERELL, 1987; GERGEN, 1985).

$\mathrm{Na}$ história da psicologia social, é notório o papel atribuído à linguagem na constituição dos processos psicossociais. No entanto, ela tem sido vista predominantemente pelos teóricos que fizeram a história dessa disciplina como um meio neutro, cuja única função é expressar pensamentos, sentimentos e outras entidades psicológicas. Mas, nas últimas três décadas, a psicologia social vem dando lugar ao reconhecimento do papel fundamental da linguagem e do discurso na construção do psiquismo humano e das relações sociais. No contexto acadêmico atual, uma consequência desse processo é a existência de um conjunto de abordagens discursivas na psicologia social, que se fundamentam, epistemologicamente, no construcionismo, lutando e se posicionando de maneira crítica em relação às abordagens tradicionais.

Nessa perspectiva, um pressuposto central é a ideia de que usar a linguagem é uma forma de ação como qualquer outra. Assim, quando construímos versões sobre o mundo, quando argumentamos, descrevemos, narramos, explicamos etc, estamos realizando ações (SPINK; FREZZA, 1999).

As abordagens discursivas são marcadamente anticognitivistas, enquanto as abordagens cognitivistas compartilham da noção de representações mentais internas e entendem a cognição como anterior à linguagem e esta última como o meio através do qual a cognição se expressa, as abordagens discursivas procuram destacar o modo como a linguagem constitui formas de experienciar o mundo (AUGOUSTINOS, 1995).

Neste texto, o interesse pela análise dos sentidos produzidos discursivamente sobre as residências terapêuticas e seus habitantes é 
uma decorrência do pressuposto de que tais sentidos constituem a experiência desses sujeitos e de seus interlocutores sobre esses objetos sociais.

Portanto, compreender esses sentidos certamente nos dará indicações sobre as tensões, as contradições e as possíveis resistências que marcam o diálogo desses sujeitos com discursos e instituições ligados à reforma psiquiátrica brasileira.

\section{Metodologia}

Em Campina Grande, o processo de Reforma Psiquiátrica materializa-se, atualmente, na existência de uma Unidade de Referência em Saúde Mental; um Centro de Convivência de Artes e Ofícios; seis residências terapêuticas e cinco Centros de Atenção Psicossocial (CAPS), sendo que um deles, o CAPS ad, atende, exclusivamente, a usuários de álcool e de outras drogas, e outros dois são CAPS-i para atenção infanto-juvenil.

Desenvolvemos uma pesquisa qualitativa e recorremos à metodologia qualitativa da História Oral como estratégia de geração de dados. Para isso, foram obtidos 24 (vinte e quatro) depoimentos orais - onze de entrevistados do sexo masculino e treze do sexo feminino - cujas idades variam de 22 a 78 anos - que moram próximos às residências terapêuticas, três das quais são masculinas (uma localizada no Bairro das Nações, uma, no Cruzeiro, e outra, no Centro), uma mista (localizada no Bairro das Nações), e duas femininas (localizadas no Bairro do Alto Branco), onde moram os usuários egressos do Instituto Campinense de Neuropsiquiatria e Reabilitação Funcional (ICANERF), que foi desativado em 2005.

O número de entrevistados foi delimitado pelos critérios de acessibilidade e do ponto de saturação. Este último indica que já se dispõe de informações suficientes sobre determinado aspecto, pois 
a análise acompanha todo o processo de pesquisa e permite que constatemos, nas entrevistas, uma repetição dos conteúdos, indicando que já podemos encerrar a coleta de dados após a obtenção de mais algumas entrevistas (LANG; CAMPOS; DERMATINI, 2001) e recorremos à técnica de análise do discurso, desenvolvida por psicólogos sociais de orientação discursiva (WETHERELL; POTTER, 1992; POTTER; WETHERELL, 1987).

\section{Os sentidos construídos nos discursos}

Segundo Resende (2000), na realidade, a finalidade social dos hospitais psiquiátricos era a de serem verdadeiros depósitos humanos, que nada tinham de terapêuticos. A fala de David, abaixo, reitera essa ideia, entretanto, transfere essa definição dos hospitais psiquiátricos para as residências terapêuticas:

Eu acho... Penso eu (ênfase) como os familiares não têm condições de ficar, com... eles, em casa, e... como eram... vieram de... de... do hospital que fechou. (...) Eu soube que é uma forma de... de... não sei se, estaria certo meu termo, um depósito de doentes, né? Pra tirar (ênfase) do convívio da família, pra... ficar aí, né? (...) As pessoas que não ficam com ele em casa, porque até mesmo acho que tem certos... certos doentes mentais que não... têm mesmo como conviver em casa mesmo com a família, e são... colocados aí... (David 4, 41 anos; há vinte e oito anos reside no Bairro Alto Branco - vizinho da residência terapêutica)

4 Para garantir o anonimato dos entrevistados e demais pessoas citadas nos discursos, foram utilizados pseudônimos. 
David adota, nas suas palavras, um tom dubitativo, em relação ao modo de qualificar as residências terapêuticas, embora não o comprometa tanto com aquilo que é afirmado, termina por posicioná-lo para o interlocutor como alguém atualizado com certo vocabulário crítico. Se o que ele afirma "soube" de alguém, se ele não está bem certo da adequação do termo "depósito de doentes", é ele, de qualquer forma, que está usando o termo em questão.

Esse discurso indica que, apesar da crescente visibilidade da proposta preconizada pela Reforma Psiquiátrica, com a desospitalização, os termos e as metáforas usados para descrever e interpretar os hospitais psiquiátricos continuam sendo usados e, ironicamente, para descrever uma instituição que o discurso reformista apresenta como a antítese da psiquiatria asilar. Elas aparecem, na sequência discursiva acima, como instituições que substituem os hospitais simplesmente porque eles "fecharam". Nenhuma diferença entre as duas entidades é citada; a residência é descrita como se tivesse as mesmas funções do hospital psiquiátrico.

Em sua fala, David, além de não diferenciar as residências dos hospitais, também justifica a sua suposta função de separar da família e da sociedade "certos doentes mentais" com os quais não se pode "conviver", reproduzindo uma velha compreensão da loucura na qual os loucos, em família, eram considerados um "perigo solto" (PEREIRA, 1983).

Já no discurso de Márcia, a seguir, a residência terapêutica assume sentidos totalmente diferentes do apresentado por David:

A residência? Eu... eu acho que é um asilo de velho.(...) Eu acho que é... assim... eu vim descobrir agora a pouco que era isso, sabe? Porque... passava lá via gritos... essas coisas assim.(...) Aí um dia eu encontrei uma moça que vinha com uma velhinha dali, sabe? E a velhinha, gritando com ela... aí eu disse assim: "Meu Deus o que será aí essa casa?” Todo dia eu passava pra 
levar a menina no colégio e escutava gente... gritando... coisas estranhas...(...) Aí eu falei assim, eu disse assim: "Dona Paula eu acho que isso aqui é um asilo de velho..." aí... quando foi um dia... aí, tem um buraco lá na porta... aí... eu olhei...aí...um monte de velho...aí... ia saindo uma senhora de lá...aí eu disse assim: "Isso aí é o quê??" Aí... ela disse assim: "É um asilo." Eu disse: "É um asilo?" Uma casa assim sem nome e sem nada, né?(...) Ai eu cheguei em casa e falei com a minha patroa. (...) Ai ela disse assim: "É um..." Eu disse assim: "Dona Paula é um asilo, mas como tem um asilo assim sem ter nada?." Aí.. ela disse: "Deve ser clandestino..." Aí a partir desse dia eu vejo carro saindo de lá com um velho da Secretaria da Saúde e... ambulância pra tirar eles daí pra ir pra hospitais... assim o que eu sei é isso... eu acho que é... passa tanto velho ali junto... e é um casarão... e é um casarão como esse, né? Deve ter vários quartos (...) Vem... eu já vi... várias... vem... gente visitar (pausa) eu num sei se é particular também, né? (...) Pode ser até uma casa particular que eles pagam pra ficar, né? num tem? Uma tipo... casa de repouso. (...) uma casa de repouso... eu acho... e muito mal... organizada, né? Não é divulgada. (...) Não. Porque... eu vim morar aqui, eu vim saber que tinha essa casa depois de uns seis meses que eu estava aqui... (...) Como a casa de apoio aí também que tem... que foi... foi uma boa iniciativa também e eu não sabia. (...) são coisas que fazem e não divulgam, né? Até porque se você... tiver que indicar a alguém você nunca vai saber... Se não é divulgado... Se, se... a gente não tom... não tem acesso ao que acontece. (Márcia, 48 anos; há dois anos reside no Bairro Alto Branco - sua residência dista três casas da residência terapêutica) 
Seu discurso, como o de David, denota também um tom de dúvida. No entanto, o objeto de dúvida expresso por Márcia é a expressão a ser usada para qualificar os moradores da residência. Nesse discurso, a natureza da instituição e a identidade dos moradores são incertas: "A residência? Eu... eu acho que é um asilo de velho".

A identidade que ela apresenta para aqueles que habitam as residências se distancia, num primeiro momento, daquilo que eles são nos discursos das instituições psiquiátricas e da sociedade. São "velhos", não são "doentes mentais", "loucos”, ou qualquer termo classificatório de origem psiquiátrica.

Assim, à medida que prossegue seu depoimento, os termos utilizados para descrever as residências terapêuticas vão se alterando. São apagadas as referências aos habitantes da casa ("essa casa", "asilo", "casa de repouso"), que vai se tornando cada vez mais misteriosa; uma casa de funções indefinidas, onde ocorrem "coisas estranhas". Uma casa que se torna estranhamente próxima daquilo que se supõe ser o universo da loucura. Sem citar um só termo do vocabulário psiquiátrico usado para descrever o sofrimento psíquico, Márcia, involuntariamente, descreve a residência de sua comunidade de uma maneira que a deixa estranhamente parecida com a imagem construída no Ocidente para descrever o universo da loucura. A residência é retratada como um lugar enigmático, onde há desespero, confusão, onde ocorrem "coisas estranhas".

A opinião de Márcia, assim como a de outros entrevistados, caracteriza-se, principalmente, pelo fato de indicar que as residências estão segregadas em relação ao próprio espaço no qual estão inseridas, porquanto não se sabe muito bem o que realmente são. Esses discursos apontam para o isolamento da residência terapêutica em relação ao espaço circundante.

O termo “casa de repouso" utilizado por Márcia também é utilizado por Aparecida. Todavia, na entrevista de Márcia, os usuários da 
casa de repouso não são nomeados de maneira inequívoca ao longo de toda a sua fala (no início, são os "velhos", mas depois, podem ser qualquer categoria social). Já para Aparecida, a casa de repouso é inequivocamente um local para "doentes mentais", como podemos constatar nesta sequência discursiva:

Eu acho o seguinte: que essas casas, que são várias não são, né? Uma só, eu acho que eles deviam assim botar ou construir ou arranjar uma casa grande pra botar essas digamos, três quatro residências alugadas, tá uma só e cuidar deles ali como (pausa) como uma casa de repouso, né? Eu acho isso. (...) Sim, e com terapias para eles que são doentes mentais, né? (Aparecida, 60 anos; há cinco anos, reside no Bairro Alto Branco - reside do lado oposto da residência, passando três casas)

Aparecida se distancia explicitamente da concepção de residência terapêutica defendida pela Reforma Psiquiátrica, que ela encontra materializada em seu bairro. A concepção desenhada por ela se aproxima mais do modelo hospitalocêntrico, em que uma grande quantidade de pessoas se encontra internada em um mesmo lugar.

Já no retrato das residências produzido por Henrique, a identidade dos seus habitantes se torna mais heterogênea do que nas falas dos sujeitos supracitados, e diferentes categorias de pessoas são citadas: pessoas que vivem "abandonadas", "pessoas de idade", "doentes mentais":

É um tratamento que cuida das pessoas, deve ser alguém assim abandonado, vive ai (...) é uma casa, assim, que recupera as pessoas né? São pessoas que vivem abandonadas, pessoas de idade, doentes mentais, como um refúgio para eles, assim, porque eu acho que a família 
deve abandonar, colocar eles ai, esquecem, né? Ainda bem que tem gente que toma conta deles ai, né? Não sei quem é que faz isso ai, mas acho que é um projeto bom isso aí. (Henrique, 34 anos; reside, há um ano, no Bairro Alto Branco, vizinho à Residência terapêutica)

Henrique expressa que a residência não é um lugar por meio do qual as pessoas estabelecem novas relações sociais em suas comunidades. É um “refúgio” que vai protegê-las, mas também isolá-las do mundo exterior, um lugar extremamente semelhante à imagem dos hospitais psiquiátricos construída historicamente, para pessoas "abandonadas", "esquecidas", estorvos familiares.

Se o louco é concebido como alguém incapaz de exercer a cidadania, o isolamento, então, é um recurso necessário para retirá-lo de um estado confuso e desordenado, internando-o numa instituição disciplinar, na qual é submetido ao "tratamento" (AMARANTE, 1995).

Assim como Henrique, Alberto também aproxima simbolicamente as residências terapêuticas dos hospitais psiquiátricos ao descrevê-las como um abrigo para pessoas "abandonadas" e com "doenças mentais":

É uma residência que abriga pessoas com doenças mentais, pessoas que foram abandonadas. Pessoas que não tem ninguém (...) Que não tem uma pessoa na sua família, mas sofre de uma doença, muitas vezes não quer tratar, não quer deixar em casa e o que é que faz? Põe numa casa como essa. (...) Antes de eu vir pra aqui ela já existia. É uma casa normal, mas não tem como você olhar assim e dizer: "Ali é uma casa de pessoas com problemas... Normal”. É, a... aparentemente normal, por fora. (Alberto, 22 anos; reside, há três anos, no bairro Cruzeiro do lado oposto da rua, passando três casas) 
Os habitantes das residências, tal como os pacientes psiquiátricos, são rejeitos sociais. Pessoas que as famílias não querem mais e colocam "numa casa como essa". A residência, nesse discurso, é uma casa "aparentemente normal por fora", mas habitada por "pessoas com problemas", pela anormalidade, pela desrazão.

No depoimento de Jéssica, abaixo, a imagem da residência como um espaço da desrazão se acentua mais ainda, e ele se torna cada vez mais um hospital psiquiátrico em miniatura.

É... um... lugar... onde as pessoas, que têm dificuldades mentais (silêncio) ficam e... devem (ênfase) ter assistência... (...) É... a meu ver um abrigo é... esses, é uma proteção tanto pros doentes... mentais, como pra vizinhança (...). Porque se um doente mental ele não fizer um tratamento e não estiver num lugar adequado onde tiver um tratamento, ele... se descontrola... (Jéssica, 48 anos; há um ano, reside no Bairro Alto Branco - a duas casas da residência)

A residência é um "abrigo" que protege tanto a população comum do descontrole do "doente mental" quanto o próprio "doente mental”, de seu próprio descontrole.

Ao longo do depoimento de Jéssica, um sutil deslizamento semântico muda a imagem das residências apresentada acima. Em um tom acusatório, ela afirma que a residência é um "depósito de doentes", onde as pessoas não recebem tratamento adequado, e não, um espaço de isolamento da desrazão:

Pra mim aí não é um abrigo de, de tratamento... de doente mental não. Pra mim aí era uma casa que eles deixavam os doentes, vinha comida e... davam... e pronto! (Jéssica, 48 anos; há um ano, reside no Bairro Alto Branco - a duas casas da residência). 
Em outras opiniões, a residência é concebida como um espaço de tratamento, de apoio e recuperação de pessoas com "deficiência mental", sem que se mencione explicitamente a função de isolamento, de separação da comunidade.

É uma casa de apoio. Tem uma... de apoio, né? Pras pessoas se recuperar... (...) que tá precisando de apoio, né? (...) Pesquisadora: Para pessoas com... Com deficiências mentais, né? (Larissa, 29 anos; há quatro anos, reside no Bairro Cruzeiro - do lado oposto da rua, passando duas casas da residência terapêutica).

Pesquisadora: Uma residência terapêutica é uma casa de...

De recuperação.

Pesquisadora: Uma casa de recuperação. E nessa casa de recuperação...

Entrevistado: Ela é só feminina. (Ronaldo, 58 anos; Há oito anos, reside no Bairro Alto Branco - vizinho da residência terapêutica).

Só um abrigo, né? Pra pessoas que têm deficiência mental. (Pierre, 26 anos; há três anos, reside no Bairro das Nações - em frente à residência terapêutica).

Para Larissa, a residência terapêutica é "uma casa de apoio" para as pessoas com deficiência mental, onde elas podem "se recuperar". O discurso de Ronaldo retoma o viés da fala de Larissa, ao enfatizar também que a residência terapêutica é um local de "recuperação". Já Pierre limita a proposta das residências a ser "só um abrigo" destinado às pessoas portadoras de deficiência mental.

Nas falas de Ana, Sônia e Talita, abaixo, a residência continua a ser apresentada, implicita ou explicitamente, como um espaço de tratamento psicológico e médico, mas novos termos, mais ambíguos, 
indefinidos, "suaves" são usados para nomear os seus residentes: "pessoas com problema", "pessoas que precisam", "pessoas com esse tipo de problema":

Não... (ênfase)... isso não é divulgado. (...) Eu vim tomar conhecimento, porque (ênfase) alguém perguntou... chegou aqui, bateu na minha porta e perguntou: "Onde é a casa... de pessoas com problema?" (...) "eu não sei nem se existe (risos) aqui nessa rua". Quer dizer, é uma coisa que não é divulgada. (Ana, 51anos; há um ano e meio, reside no Centro - do lado oposto da residência terapêutica passando quatro casas)

É uma casa de fazer terapia, né? (...) É a única coisa que eu sei. (...) Eu acho que é uma casa de ajuda pra quem precisa, né? (...) Uma casa de terapia para pessoas que precisam daquele movimento. (Sônia, 78 anos; há quinze anos, reside no Bairro Alto Branco - reside numa rua transversal à rua da residência terapêutica)

É uma residência onde eles acolhem essas pessoas com esse tipo de problema pra fazer um tratamento, um acompanhamento (...) Como tratamento médico, psicológico. Acho que, que engloba tudo (...) um lugar que eles vão ser bem acolhidos, bem tratados... (...) Eu imagino que seja um lugar bom (risos) (...) que a família dessas pessoas não tiveram é... (pausa) como tratar delas, não sabiam como fazer assim... num momento assim... que eles procuraram esse lugar pra ter uma ajuda, pra dá uma ajuda pra essas pessoas, porque eles não sabiam como fazer. (Talita, 25 anos; há sete anos, reside no Bairro Alto Branco - Terceira casa depois da residência) 
A residência é também construída discursivamente como um local destinado a acolher pessoas de baixa renda, "carentes", "necessitadas", "deserdadas":

É como eu tô dizendo, eu acho que do jeito que está essa casa aqui, eu tenho certeza que as outras também tão... não sei lhe dizer quantas casas são... distribuídas aqui na cidade, mas eu sei que aqui no Alto Branco tem uma, e ali em cima tem outra... agora a rua eu não sei dizer, mas sei que são duas casas só no Alto Branco... para atender essas pessoas carentes e necessitadas. (Amanda, 40 anos; há dezessete anos, reside no bairro Alto Branco - vizinha da residência terapêutica)

Olha, pra mim é um acolhimento (...) Essa residência pra mim é um lar, é um abrigo de amparo a essas pessoas deserdadas da sorte (...) A dormida tudo é aí... é como se fosse o lar deles. (José, 67 anos; há dezesseis anos, reside no bairro do Cruzeiro - do lado oposto da residência terapêutica, passando uma casa)

A ideia de abrigo que aparece em outros discursos, como vimos, consolida-se nas falas acima, que ressaltam o caráter de assistência das residências, considerando-as como lugares para pessoas carentes e necessitadas. José enfatiza outro aspecto que merece ser destacado: o fato de que a residência é "um acolhimento", "um lar" "um abrigo de amparo". É "como se fosse o lar deles", e se é "como se fosse", não é o lar deles. A residência, então, seria uma invenção. Algo que tenta reproduzir uma relação familiar, mas que não é capaz de fazê-lo, o que nos remete à questão do tipo de abrigo como "o lar dos velhinhos". 
Numa mudança considerável, em relação às falas anteriores, o termo CAPS é usado em alguns depoimentos para nomear a residência, como expressam os trechos seguintes:

$E$ E, assi... eu... eu... assim, pessoalmente eu não frequento muito (...) Sei que, tem assim essas casas de yoga, essas coisas assim, mais terapêutica assim, mais específicas, não (...) Eu não, realmente eu não... eu sei que existe assim... é... casa de yoga, essas coisas, aqui, aqui tem o quê... tem, o pessoal que faz hidroginástica, esse tipo de coisa né? assim, mas (pausa) qual o tipo de terapia mais específica, porque tem o CAPS ali em baixo também, né? (...) É... assim, de certa maneira o CAPS hoje, veio fazer com que... tivesse... um... uma maior... assim atenção, pra esse tipo de, de, de... pessoal né? que necessita de ajuda, tudo, que antes, não... tinha, tinha que... se (ênfase) a família tivesse condições, fazia isso numa clínica particular, esse tipo de coisa né? (Gabriel, 25 anos; há vinte e cinco anos, reside no bairro Alto Branco - na rua transversal, passando cinco casas da residência terapêutica)

O que eu acho... é uma iniciativa muito boa... do governo federal junto com a prefeitura. É o CAPS no caso, eu acho muito bom, as famílias acham muito bom também, porque esse é um meio que elas tem de manter esse paciente em casa. Eles tem tratamento psicológico, tem tratamento com medicamentos correto. $E$ aí eles tem uma boa alimentação, tem um acompanhamento, tem uma área de lazer que eles participam, tem todo um acompanhamento que eu acho muito bom, essa residência terapêutica. (...) Tinha alguns que estavam ali... onde fechou, no João Ribeiro [refere-se ao 
Instituto Campinense de Neuropsiquiatria e Reabilitação Funcional(ICANERF), que foi desativado na cidade de Campina Grande] aí... foram transferidos para a casa terapêutica. (...) E alguns de doutor Maia também. (...) Não só pra esse aqui, pois tem vários CAPS aqui em Campina. (Andréia, 22 anos; há 20 anos, reside no bairro do Cruzeiro - uma casa depois da residência terapêutica)

Pessoas que convivem, né? No CAPS aí. (...) É (...) Pelo menos aparentemente. No dia que eu fui lá (pausa) é como se fosse uma residência normal. (...) Uma pessoa sentada na mesa... conversando. Os funcionários tratando como se fosse... sei lá... pessoas da família. O que eu pude notar é isso. Não tem, agressão física, violência... não tem... eles não impedem da, dos... do pessoal ir e vir, sair da residência quando eles quiserem. (Júlio, 29 anos; há 15 anos, reside no bairro Alto Branco - reside numa rua transversal à rua da residência terapêutica)

(...) Às vezes a gente passa aí na frente dá pra ver a sala de TV... todas as vezes que eu passo eles estão bem quietinhos assistido televisão (...) São... assim, por ser uma residência, né? Não tem como você escolher uma residência num lugar que não seja um bairro, uma rua, um lugar que tem outras casas, né? Eu acredito que a intenção quando se criou essa história de CAPS, acho era isso... achar uma residência, uma coisa, né? Informal assim e que passe... que tenha pra passar pros enfermos uma qualidade melhor de vida. Eu acredito que... tá tudo correto (pausa) não poderia ser diferente. Acredito. (...) Pelo que me informam é um CAPS, né? (...) Isso aí é o CAPS. (...) Acredito o que qualquer uma pessoa poderia pensar. É um... uma... 
unidade de... de terapia para pessoas com problemas mentais, num é? É... patrocinado pelo... pela prefeitura... (Roberto, 29 anos; há 25 anos, reside no bairro Alto Branco - duas casas depois da residência terapêutica)

Embora Gabriel empregue o termo CAPS, não há qualquer outra aproximação mais clara com o universo discursivo da reforma psiquiátrica. A casa é um local para pessoas que necessitam de "ajuda".

A fala de Andréia, por outro lado, aproxima-se, em termos de conteúdo, do discurso reformista, porquanto enfatiza que o objetivo do "CAPS" é "manter esse paciente em casa". Diferentemente de discursos ouvidos anteriormente, aqui, a ideia de separar o "paciente" da comunidade não só está ausente, mas também é implicitamente combatida na medida em que se elogia a permanência do paciente junto da família.

Gabriel, Júlio e Roberto também usam o termo CAPS para falar da residência terapêutica de seu bairro. Seus discursos, de maneira mais consistente e articulada do que o de Andréia, mobilizam termos do vocabulário da Reforma e combatem o modelo hospitalocêntrico. Esse modelo é combatido sem que seja citado explicitamente.

As características do novo modelo, citadas em seus discursos, são contrárias às do modelo asilar. Nas residências, "não tem agressão física, "violência", as pessoas podem "ir e vir", "sair da residência quando eles quiserem". As "pessoas" (no discurso de Júlio) ou os "doentes mentais" (no discurso de Roberto) são tratados como os outros cidadãos. Como que dialogando com discursos que expressam incômodo pela presença da residência em seu bairro, Roberto afirma que ela é assim "por ser uma residência”. E continua: "Não tem como você escolher uma residência num lugar que não seja um bairro, uma rua, um lugar que tem outras casas, né?" 
Os discursos de Glória, Andréia, Júlio e Roberto mobilizam termos e expressões do discurso reformista e citam, explicitamente e diferente desses últimos, a reforma psiquiátrica ("essa Reforma”).

Eu acho que é a modernização da... da... do tratamento do... das pessoas com... com... enfermidades mentais, que... evoluiu de... de dar choques, né? evoluiu de... de isolar, segregar, é uma evolução muito grande, eu acho que é um ponto extremamente positivo no tratamento dos doentes. (...) achei que foi um avanço da psiquiatria... ou talvez da psicologia, acho que mais da psiquiatria, né? Achei que foi um avanço enorme, enorme no tratamento (pausa) e eu acho acho muito (ênfase) positivo porque eles moram em casa, tem as empregadas, tem o vigia, a família vem sempre (ênfase) aí, eles, eles passeiam, levam eles numa... tem uma combe levam eles pra passear, pra visitar a família, a família vem... tem uns que os pais vêm diariamente dar banho... tudo (...) deve ser essa Reforma, deve ser isso, um tratamento humanizado, e tirar... daquele... onde eles ficavam naquele isolamento, colocar numa residência, dar a ele um... um.... um... um... um aspecto de lar (ênfase)... eles tem aí... é uma casa é um lar (...) é um lar porque tem tudo que você... (...) Porque se você entrar aí você vê olha o que tem... tem televisão...(...) Pra eles tem jogo, eles jogam totó (...) é uma casa, com quarto, com tudo (...)" (Glória, 67 anos; há mais de trinta anos, reside no Bairro das Nações - do lado oposto da residência terapêutica, passando uma casa). 
De maneira mais evidente do que aparece nos discursos de Andréia, nas falas de Júlio e de Roberto, esses termos se misturam com outros do discurso psiquiátrico tradicional.

Para ela, diferentemente do modelo anterior, o modelo implantado pela reforma não isola, não segrega as pessoascom "enfermidades mentais", "doentes". Em outros momentos, no entanto, afirma que é um avanço da "psiquiatria", quando se sabe que se pretende "antipsiquiátrica", e usa a ambígua expressão "tratamento humanizado", expressão incômoda para o discurso reformista, por sua associação com o argumento da psiquiatria tradicional, segundo o qual a instituição hospitalar poderia ser preservada, desde que se tornasse "mais humana".

Assim como José, Glória ressalta, ainda, como já citado, o "aspecto de lar" da residência (os passeios, visitas, etc.), bem como o que existe em seu interior, aquilo que, para ela, faz dela "uma casa", "um lar" (quarto, televisão, jogos).

\section{Considerações finais}

Neste texto, apresentamos parte dos resultados de uma pesquisa que realizamos sobre os sentidos atribuídos às residências terapêuticas pela população dos bairros onde essas residências estão localizadas em Campina Grande/PB. Essa pesquisa se desenvolveu através de uma proposta que privilegia o estudo da produção de sentidos por meio da análise das práticas discursivas.

Com base nas análises dos depoimentos dos entrevistados, podemos referir que diferentes sentidos são construídos para as residências terapêuticas, o que demonstra, em alguns casos, que há um distanciamento da proposta da Reforma Psiquiátrica e, em outros, uma aproximação gradativa dessa proposta. Assim, a residência é concebida como "depósito de doentes", "asilo de velho", "casa de 
apoio/repouso, pessoas com problema, pessoas carentes”, “auxílio psicológico, acolhimento e abrigo de amparo" e como o "CAPS".

O fator doença aparece, sobremaneira, nos discursos como responsável pela impossibilidade de um convívio social, ou seja, como uma "deficiência" que resulta no isolamento desses sujeitos. O caráter assistencial das residências é reiterado em muitos discursos.

No contexto da Reforma Psiquiátrica, deparamo-nos com discursos que, em geral, reproduzem sentidos vinculados às antigas práticas asilares. Isso serve de alerta para os grandes desafios que ainda precisam ser enfrentados no processo de concretização dessa proposta.

\section{Referências}

AMARANTE, P. A (clínica) e a Reforma Psiquiátrica. Curso de Especialização em Saúde Mental e Atenção Psicossocial. Campina Grande: FIOCRUZ/UEPB, 2007.

. Uma aventura no manicômio. História, Ciências, Saúde Manguinhos, v. 2, n. 1, p. 61-77, 1995.

AUGOUSTINOS, M.; WALKER, I. Social Cognition: an integrated introduction. London: Sage Publications, 1995.

BRASIL. Ministério da Saúde. Secretaria de Atenção à Saúde. Residências Terapêuticas: o que são, para que servem. Brasília: Ministério da Saúde, 2004.

GERGEN, K. J. The Social Constructionist Movement in Modern Psychology. American Psychologist, v. 40, n. 3, p. 266-275, 1985. 
LANG, A. B. S. G.; CAMPOS, M. C. S. S.; DERMATINI, Z. B. S. História oral e pesquisa sociológica: a experiência do CERU. $29^{\circ}$ ed. São Paulo: Humanitas, 2001.

PEREIRA, J. F. O que é loucura. 2 a ed. São Paulo: Brasiliense, 1983.

POTTER, J. La representación de la realidad: discurso, retórica y construcción social. Barcelona: Paidós, 1998.

POTTER, J.; WETHERELL, M. Discourse and Social Psychology: beyond attitudes and behavior. London: Sage Publications, 1987.

RESENDE, H. Política de saúde mental no Brasil: uma visão histórica. In: ALMEIDA, S. T.; COSTA, N. (Orgs.). Cidadania e loucura: políticas de saúde mental no Brasil. $6^{\circ}$ ed. Rio de Janeiro: Vozes, 2000.

SPINK, M. J.; FREZZA, R. M. Práticas discursivas e produção de sentidos: a perspectiva da Psicologia Social. In: SPINK, M. J. (Org.). Práticas discursivas e produção de sentidos no cotidiano: aproximações teóricas e metodológicas. São Paulo: Cortez, 1999.

WETHERELL, M.; POTTER, J. Mapping the Language of Racism: discourse and the legitimation of exploitation. London: Harvester Wheat Sheaf, 1992. 